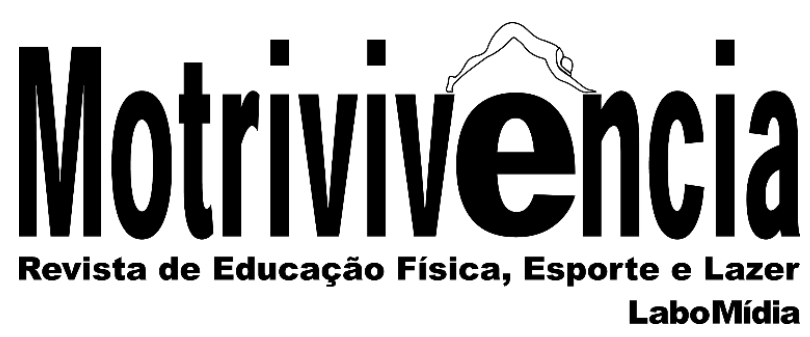

\title{
A escola sem corpo: considerações acerca da crise de legitimidade da Educação Física
}

\section{RESUMO}

Este trabalho consiste em discutir a crise de legitimidade da Educação Física escolar a partir da categoria "corpo". Questiona-se sobre o descrédito da disciplina na ambiência escolar, apesar da sua legalidade e inquestionáveis avanços teóricos. Destaca-se a relação intrínseca entre corpo e escola na consolidação do projeto capitalista. Avança nas reflexões contextualizando o debate em torno do Movimento Renovador da Educação Física, especialmente sobre a pedagogia crítica de orientação marxista. Aponta limites nas suas acepções de corpo, no geral, instrumentalizado em prol da assimilação de conteúdo mental ou da consciência crítica. Não se trata, com isto, de negar as formas clássicas de educação escolar, mas de afirmar o lugar do corpo e, para extensão, das práticas corporais e da Educação Física na escolarização de crianças, jovens e adultos, já que a própria estrutura (física e teórica) escolar foi historicamente projetada de modo a negar e imobilizar a corporalidade dos indivíduos.

PALAVRAS-CHAVE: Escola; Educação física escolar; Legitimidade; Corpo; Pedagogia marxista
Harrison de Souza Bezerra

Graduação em Educação Física

Universidade Federal do Pará,

Campus Castanhal, Brasil

Prof. do Ensino Básico do município de

Castanhal, Pará

harrisonbezerra2017@gmail.com

[D https://orcid.org/0000-0002-3475-8763

Renan Santos Furtado

Doutorando em Educação

Universidade Federal do Pará,

Professor da Escola de Aplicação da

Universidade Federal do Pará

Belém, Brasil

renanfurtado@ufpa.br

https://orcid.org/0000-0001-7871-2030 


\title{
The school without body: considerations about the legitimacy crisis of Physical Education
}

\begin{abstract}
This article discusses the legitimacy crisis of school's Physical Education from the "body" category. It brings questions about the discredit of the discipline in the school environment, despite its legality and unquestionable theory advances. Underscore the intrinsic connection, between body and school in the capitalist project consolidation. It advances in reflections to contextualize the debate about the Renewal Movement of Physical Education, particularly about critical pedagogy of Marxist orientation. On the whole, it points to limits in its meaning of the instrumentalized body in favor of a mental content assimilation or critical awareness. It is not meant to deny the classical forms of school education but to affirm the place of the body and, for extension, also to affirm the body practices and physical education in the children, young, and adults schooling, since the (physical and theoretical) school structure itself was historically designed to deny and immobilize the individuals corporeality.
\end{abstract}

KEYWORDS: School; School's physical education; Legitimacy; Body; Marxist pedagogy

\section{La escuela sin cuerpo: consideraciones sobre la crisis de legitimidad de la Educación Física}

\section{RESUMEN}

Este trabajo consiste en discutir la crisis de legitimidad de la Educación Física escolar a partir de la categoría "cuerpo". Se cuestiona el descrédito de la disciplina en el ámbito escolar, aunque su legalidad y avances teóricos sean incuestionables. Destaca la relación intrínseca entre cuerpo y escuela en la consolidación del proyecto capitalista. Avances en las reflexiones, contextualizando el debate en torno del Movimiento Renovador de la Educación Física, en especial, sobre la pedagogía crítica con orientación marxista. Señala límites en sus significados del cuerpo, en general, instrumentalizados a favor de la asimilación de contenidos mentales o conciencia crítica. No se trata de negar las formas clásicas de educación escolar, sino de afirmar el lugar del cuerpo, y, en cierta medida, de las prácticas corporales y la Educación Física en la escolarización de niños, jóvenes y adultos, ya que la propia estructura (física y teórica) de la escuela ha sido diseñada históricamente para negar e inmovilizar la corporeidad de los individuos.

PALABRAS-CLAVE: Escuela; Educación física escolar; Legitimidad; Cuerpo; Pedagogía marxista 


\section{INTRODUÇÃO}

No acalorado debate sobre a legitimidade da Educação Física escolar, há uma série de discussões no sentido de se pensar por quais motivos, apesar da disciplina fazer parte dos currículos escolares há pelo menos 150 anos, de modo mais ou menos constante na Europa e no Brasil, ainda assim, invariavelmente, levantam-se questionamentos sobre a sua contribuição no projeto educacional que se perspectiva para a escola contemporânea.

Desde as atuais políticas de currículo, como a Base Nacional Comum Curricular (BNCC) homologada em 2017 sob o parecer no 15/2017 do Conselho Nacional de Educação (CNE); e a Reforma do Ensino Médio instituída pela Lei $n^{\circ}$ 13. 415 de fevereiro de 2017; perpassando pela cultura escolar que tradicionalmente hierarquiza disciplinas e campos de conhecimento (BRACHT; ALMEIDA; WENETZ, 2018), a Educação Física tem sofrido diversos questionamentos sobre qual seria de fato a sua contribuição formativa na escolarização básica das crianças, jovens e adultos que frequentam a escola brasileira.

Cientes de que em termos de justificativa da razão de ser da Educação Física na escola, legalidade não significa legitimidade (BRACHT, 1997), o campo acadêmico da área identificado com as discussões educacionais tem tentado, desde a década de 1980, construir uma série de discursos e algumas propostas didático-metodológicas que apontem para a consolidação de um objeto de intervenção e o estabelecimento de objetivos educacionais com base no debate pedagógico brasileiro de orientação crítica. Como exemplo deste empreendimento, temos as obras de Freire (1989), Soares et al. (1992) e Kunz (1994).

Todavia, após o período de maior efervescência do chamado Movimento Renovador da Educação Física brasileira ${ }^{1}$, constatou-se que os avanços teóricos do campo acadêmico não necessariamente se reverteram em avanços práticos nas intervenções pedagógicas com as práticas corporais nas escolas. Ou mesmo em uma maior credibilidade da disciplina dentro da cultura escolar (MACHADO et al., 2010; BRACHT; ALMEIDA; WENETZ, 2018).

\footnotetext{
${ }^{1}$ O movimento Renovador da Educação Física brasileira pode ser compreendido como uma inflexão na área a partir da década de 1980, período em que emergiu uma produção de conhecimento e movimentos político-pedagógicos críticos às tradições médica, militar e esportiva que constituíram a base da consolidação da Educação Física na modernidade. Do ponto de vista de suas lutas e reivindicações, a pauta da consideração legal/legislativa da Educação Física como componente curricular obrigatório na escola pode ser concebida como um consenso entre todos os sujeitos envolvidos no movimento (MACHADO; BRACHT, 2016). De acordo com Vaz (2019), é possível dizer que além da crítica ao esporte tradicional, e das ideias e práticas higienistas e militarizadas, o movimento carrega em si uma forte denúncia ao sufocamento do corpo pela ordem disciplinar dominante na sociedade moderna. Almeida, Bracht e Vaz (2015) apontam que inicialmente o movimento renovador atuou como uma frente ampla que buscava transformar a disciplina de Educação Física e conferir-lhe maior cientificidade. Posteriormente, as distintas concepções de ciência e sobre a relação entre política e educação fizeram com que diferentes orientações e campos teóricos se estabelecessem na área.
} 
Nesse sentido, mesmo que diversas iniciativas de pesquisas apontem para a emergência de práticas pedagógicas inovadoras e progressistas na Educação Física escolar (MALDONADO et al., 2018), é evidente que os problemas de legitimidade deste componente curricular dificilmente serão resolvidos com ações isoladas. Embora, se tenha as melhores intenções.

Outro elemento interessante para a reflexão é pensar os problemas da Educação Física em consonância com a crise da educação brasileira, no que diz respeito às dificuldades estruturais na consolidação de carreiras atrativas para o magistério, melhores condições de trabalho, desenvolvimento de práticas na formação continuada de professores etc. Logo, dispensa maiores explicações afirmar que o tema aqui tratado possui uma dimensão política intrínseca.

Sem dúvida alguma, apesar dos inegáveis avanços epistemológicos e pedagógicos da Educação Física, a percepção de que não saímos da crise demonstra também o movimento do campo no sentido de projetar a possibilidade de atualizarmos o projeto educacional crítico para as demandas do presente. Esta tarefa requer pensar formas de aprendizagem para além dos modelos cognitivistas. Não se trata de negar a importância da instrumentalização teórica na escolarização das crianças, jovens e adultos. Tampouco fazer conflito com outras áreas de conhecimento; mas, de afirmar o lugar do corpo e, por conseguinte, das práticas corporais e da Educação Física na ambiência escolar².

Seria igualmente importante refletirmos se a ideia de que estamos em crise de legitimidade escolar e social na área da Educação Física não escancara certo "comodismo" da escola e de outras áreas de conhecimento que compõem o currículo escolar. Grosso modo, se as coisas não estão "indo tão bem" na Educação Física, o que nos faz pensar que nas outras disciplinas existe uma transposição mais consolidada do debate crítico-reflexivo em educação nas práticas de escolarização? A crise em torno da Educação Física não seria também uma crise da própria instituição escolar?

Nesse sentido, propomo-nos a discutir a crise de legitimidade da Educação Física a partir da escola. Ou melhor dizendo, por via de um aspecto específico da educação escolar, que é a sua relação com o corpo. Apostamos na hipótese de que de algum modo a escola é avessa ao corpo e ao movimento. Por isso, a Educação Física, como disciplina que tematiza as manifestações da cultura que se expressam pelo corpo, é vista como um conjunto de atividades que não contribui para o tipo

\footnotetext{
2 Conforme argumenta Silva (2014, p. 13), “[...] os conceitos de corpo e práticas corporais são mutuamente referenciados por sua conexão teórico-prática intrínseca". Neste sentido, será comum o leitor encontrar ao longo do texto a categoria "práticas corporais" inserida nas reflexões sobre o corpo. Se o corpo, na perspectiva da Educação Física escolar, manifesta-se sobretudo pelas práticas corporais (jogos, brincadeiras, esportes, ginástica, lutas, dança etc.) fica posto, de igual modo, que tais práticas corporais "explicitam-se principalmente no corpo e pelo corpo" (Ibid., p. $14)$.
} 
de educação que ali se perspectiva, que é, em geral, cognitivista e com fins utilitários ao mercado da força de trabalho.

Nesse sentido, esta pesquisa apresenta como objeto de estudo a reflexão sobre a escola e o corpo e suas implicações para a legitimidade da Educação Física, enquanto disciplina que expressa e tematiza um saber eminentemente corporal. Em termos metodológicos, fundamenta-se em uma bibliografia especializada dos campos da educação e Educação Física - que aponta considerações importantes sobre a relação entre escola, corpo e legitimidade. Enquanto empiria mais específica, trabalharemos com o exame do lugar do corpo em uma vertente da pedagogia crítica marxista da Educação Física brasileira, formulada por Soares et al. (1992).

Cabe destacar que a suspeita sobre os limites das pedagogias críticas da Educação Física brasileira já tem sido expressa na forma de produção de conhecimento por um conjunto de intelectuais do campo. Em Bracht $(2012)^{3}$ encontramos uma consistente problematização das lacunas da pedagogia crítica da Educação Física, orientada pelo marxismo e pela pedagogia histórico-crítica. Dentre as principais críticas sinalizadas por Bracht, destacamos: a dificuldade da proposta ser traduzida para a linguagem e realidade dos professores da educação básica, a crítica da concepção de história da obra, que contém traços de um certo determinismo econômico na análise do desenvolvimento da Educação Física escolar no Brasil, a organização curricular e a seleção de conteúdos baseados somente em critérios cognitivos, sem considerar o corpo.

Mais recentemente, Almeida, Bracht e Vaz (2015) e Bracht e Almeida (2019) aprofundaram o debate sobre os limites da pedagogia marxista da Educação Física em questão. Porém, com foco na crítica à compreensão de ideologia, na pretensão de alcançar a verdade absoluta e ao forte realismo presente nesta proposta, que tende a se considerar a única, ou a via mais racional para o exame da modernidade e de todas as suas manifestações ideológicas que deturpam a formação de uma consciência não alienada.

Nesse sentido, partindo das contribuições acima mencionadas, neste trabalho retomaremos a discussão sobre o lugar do corpo dentro de um projeto crítico de Educação Física, com o intuito de apontarmos possibilidades para a legitimidade da disciplina na escola contemporânea.

Para dar conta da discussão proposta, organizamos o texto em três partes. Na primeira, apresentaremos elementos para articular o debate entre escola moderna, corpo e Educação Física, com especial atenção aos dizeres sobre o corpo de uma pedagogia crítica da Educação Física brasileira. Em seguida, aprofundaremos a discussão sobre o lugar do corpo no Movimento

\footnotetext{
${ }^{3}$ Aqui fazemos menção ao texto oriundo de uma entrevista que o professor Valter Bracht concedeu em 2001 ao Grupo de Estudos Etnográficos em Educação Física e Esporte (ETHNÓS); na ocasião, para refletir sobre as contribuições, impactos e limites da obra "Metodologia de ensino de educação física" que estava prestes a completar 10 anos da publicação da sua primeira edição.
} 
Renovador da Educação Física brasileira, para assim pensarmos sobre a contribuição da produção teórica crítica da área para o avanço da relação entre conceito e experiência. Por último, expomos nossas considerações, perspectivas, reflexões e indagações, a fim de reorientar a discussão sobre o lugar do corpo e das práticas corporais na escola.

\section{A ESCOLA E O CORPO: breve excurso sobre alguns dizeres da pedagogia marxista}

É interessante notar que, numa análise que não sacrifica a história, tanto a escola como o corpo surgem, especialmente na passagem do século $\mathrm{XIX}^{4}$, como indispensáveis ao processo de consolidação da democracia burguesa. A escola moderna nasce como o grande instrumento para "vencer a barreira da ignorância" e, de igual modo, "converter os súditos em cidadãos" (SAVIANI, 2008, p. 5). O corpo, por sua vez, é socializado como força de produção, força de trabalho, máquina indispensável ao desenvolvimento do capitalismo (FOUCAULT, 1979). As luzes da razão tinham de vencer as trevas do medievo. O corpo do servo deveria ser convertido em corpo operário.

Diz-se, de modo geral, que a instituição escolar moderna "surge como um antídoto à ignorância" e, nesta perspectiva, "seu papel é difundir a instrução, transmitir os conhecimentos acumulados pela humanidade e sistematizados logicamente" (SAVIANI, 2012, p. 6). No entanto, como nos esclarece Foucault (1979, p. 80), "o controle da sociedade sobre os indivíduos não se opera simplesmente pela consciência ou pela ideologia, mas começa no corpo, com o corpo".

Se isto é verdade, que o poder coercitivo começa no corpo, com o corpo, então significa dizer que a própria escolarização, despejo verborrágico de saberes estanques, é posterior a um exercício primeiro: a disciplina ${ }^{5}$ e o controle sobre o corpo. Por isso, a escola o imobiliza e o reduz à sua composição puramente anátomo-fisiológica como condição indispensável à execução de um presunçoso racionalismo que, nas palavras de Gonçalves (1994), é essencialmente irracional.

\footnotetext{
${ }^{4} \mathrm{O}$ século XIX, em particular, marca um período de grande desenvolvimento das forças produtivas capitalistas (FOUCAULT, 1979), estabelece a constituição de importantes documentos em defesa do princípio de que a educação é direito de todos e dever do Estado (SAVIANI, 2008) e institui a socialização da Educação Física em todas as instâncias de poder onde se pudesse assegurar a construção de um "novo homem", necessário ao capital (SOARES, 2007). No limite, cabe dizer que a modernidade realiza um investimento no corpo como nunca antes na história, do "cuidar" do corpo operário. Ao comando do corpo pelas instituições republicanas e democráticas assistimos um ininterrupto processo de investimento do corpo pelo poder, tendo em vista a dominação e o controle dos indivíduos, o que caracteriza o conceito de biopoder de Foucault.

${ }^{5}$ Importante aqui sublinharmos que o filósofo Foucault (1979) fala principalmente sobre o poder disciplinar e as instituições disciplinares, isto entre os séculos XVIII, XIX e XX. Trata-se de um regime de poder onde o indivíduo não cessa de passar de um local fechado a outro: família, escola, caserna, fábrica, hospital, prisão etc. Por outro lado, Deleuze (1992) nos alerta para a crise dessas instituições e o surgimento de um novo regime, chamado de "sociedade de controle", onde esse controle é contínuo e ilimitado - o panóptico capilarizado, internalizado e melhorado. Nesta transição progressiva de um tipo de regime a outro, o corpo encontra-se nessa encruzilhada entre a disciplina e o controle.
} 
Temos assim a receita perfeita da dominação, na qual a escolarização se realiza dentro de um "cérebro" e, obrigatoriamente, num corpo domesticado. A escola, em sua estrutura física demonstra, sem qualquer constrangimento, a sua aversão ao corpo e, por conseguinte, às práticas corporais. A arquitetura da escola é anticorpo e contra o corpo. O meio-fio pontiagudo, as calçadas desalinhadas, com muitos trechos cobertos de limo e lodo, as valas abertas, o chão liso, as vigas expostas, enfim, tudo isto é como um recado para o corpo: "não corra! não suba! não pule! é perigoso! entre na fila!".

À medida, portanto, que a escola se consolida enquanto instituição de instrução e transmissão de saber, vai-se, no mesmo ritmo, construindo as concepções sobre corpo e o lugar que este corpo deve ocupar em determinado lugar da esfera social. O que se observa é que há uma relação muito próxima, indispensável, diríamos, entre escolarização e controle sobre o corpo.

Ao adentrar o currículo escolar, a Educação Física não pôde escapar a esta condição fragmentária e ontologicamente invertida, mito fundador da sociedade moderna, na qual o corpo vivo, antes participante do ato criador de transformar a natureza, e vice-versa, torna-se "um corpo mecanizado, que tem tarefas a cumprir de forma automatizada, com um mínimo de participação do espírito" (GONÇALVES, 1994, p. 63). A marca fundamental da sociedade moderna burguesa é esta, a saber, a fragmentação do humano em partes antagônicas: uma mente a ser instruída em um corpo que deve ser adestrado. Dividir para melhor governar, ou se preferirmos a linguagem da modernidade nascente dos anos 1600, trata-se de fragmentar para melhor conhecer (DESCARTES, 2009).

Freire (2014, p. 79), em sua crítica à nossa herança educacional "bancária”, escreveu: “a tônica da educação é preponderantemente esta - narrar, sempre narrar”. Ingold (2010) questiona de forma severa este pressuposto cognitivista no qual o conhecimento existe principalmente na forma de "conteúdo mental" e que, portanto, a cultura é passada de geração a geração através da transmissão e acúmulo de representações, novamente, "mentais". Se para a escola o saber é informação, a conclusão óbvia é que os "seres humanos são mecanismos para processá-lo" (INGOLD, 2010, p. 7).

Nesta direção, nota-se que corpo é reduzido tão somente a um suporte inerte da aprendizagem. O mais grave é que nessa linha acredita-se em um corpo que sustenta uma consciência, numa possível conscientização que é obtida apenas pelos mecanismos da cognição, mas que fragmenta o próprio conceito de consciência, que no sentido de Freire (1979) revela-se como "consciência mais ação" (conscientização), ou seja, uma consciência com práxis, como corpo consciente. 
Mesmo a pedagogia marxista, ao pensar as práticas corporais, não deixou de atribuir especial exagero à razão - ou à consciência, como preferem chamar. Em crítica à linha mais ortodoxa da pedagogia marxista, conhecida como "Coletivo de Autores", Vaz (2019, p. 7), constatou que em sua centralidade não está o corpo, "mas uma reflexão sobre as representações que o têm como destinatário." Ou seja, não é o corpo dotado de subjetividade, de técnica ${ }^{6}$, de história, de criatividade, de sentidos e significados que ocupava (e talvez continue não ocupando) o cerne do debate epistemológico marxista. Mas, como a produção cultural desse corpo poderia ser útil à conscientização da classe trabalhadora, ou talvez dos filhos dessa classe, ou, ainda, à consecução do projeto histórico (SOARES et al., 1992).

Não se trata aqui, sob hipótese alguma, de desprezar a importância inquestionável da obra produzida pelo Coletivo de Autores, tampouco objetar a dimensão política das práticas corporais, ou se opor ao projeto histórico socialista, mas de afirmar um lugar para o corpo que, a nosso ver, foi secundarizado no debate em favor da "consciência" - irmã siamesa da "razão" dos teóricos do iluminismo. Não nos oferece dúvidas de que há em Marx apontamentos fundamentais sobre o corpo, entretanto "o marxismo - enquanto realidade histórica - as ocultou terrivelmente em proveito da consciência e da ideologia” (FOUCAULT, 1979, p. 148).

Vejamos, por exemplo, a questão do trabalho em Marx, entendido como condição universal do metabolismo entre o ser humano e a natureza (MARX, 2013). Na ontologia marxiana, o trabalho é entendido como unidade existencial entre corpo e espírito, ou corpo e consciência. Ao mediar a relação humano, natureza e, acrescentamos, cultura, o trabalho torna-se indissociável à própria construção do sujeito humano, ou, se preferirem, para não caírem no pecado de se aproximarem de Marx, à própria construção da identidade/subjetividade. Por isso Gonçalves (1994, p. 22), ao discorrer sobre a relação entre a corporalidade humana e o modo de produção capitalista, teceu a seguinte crítica: "a redução do trabalho humano à força de trabalho, no sentido fisiológico, trouxe consigo uma dissociação entre a força criativa espiritual do homem e a força físiológica corporal, gerando um corpo autônomo, desprovido de subjetividade".

$\mathrm{Na}$ perspectiva marxiana, o trabalho, relacionando-o à corporalidade humana e às práticas corporais, está íntima e historicamente ligado a uma vivência autêntica da aprendizagem humana na qual o corpo, e não apenas uma consciência, aparece não mais como suporte, mas protagonista desse processo. Afinal, do mesmo modo que "não há uma consciência antes e um mundo depois e

\footnotetext{
6 Técnica entendida aqui "como um processo que envolve a pessoa inteira interagindo em e com o ambiente, indissociavelmente, social e natural" (DEBORTOLI; SAUTCHUK, 2013, p. 10). Ou seja, não se trata da velha acepção cartesiana onde a técnica está alienada ao indivíduo e se apresenta em "cápsulas de aprendizagem" ligada ao alto rendimento, mas, isto sim, da própria construção da pessoa na relação técnica-mundo (Ibid.). Nos termos de Adorno (2020), antes de tudo, importa pensar a técnica como extensão do braço do homem.
} 
vice-versa" (FREIRE, 2014, p. 98), não temos como sustentar o devaneio de que, por exemplo, o sistema nervoso esteja desligado do corpo e do movimento.

Nas palavras do próprio Marx (1996, p. 297), no processo de trabalho, o humano "põe em movimento as forças naturais pertencentes à sua corporalidade, [seus] braços e pernas, cabeça e mãos". Dessa forma, "agindo sobre a natureza externa e modificando-a por meio desse movimento, ele modifica, ao mesmo tempo, sua própria natureza" (MARX, 2013, p. 219). Portanto, quando Kunz (2012), professor em geral não associado diretamente ao marxismo, fala da unidade entre movimento e percepção, talvez se aproxime mais da dialética do trabalho do que os "próprios marxistas", já que, em Marx, a categoria trabalho jamais se reduziu à produção material ${ }^{7}$ (DUARTE, 2012).

\section{O MOVIMENTO RENOVADOR DA EDUCAÇÃO FÍSICA BRASILEIRA E O CORPO}

Sobre o Movimento Renovador da Educação Física brasileira, não se tem dúvida a respeito do modo como os vários discursos epistemológicos e as ações político-pedagógicas dos sujeitos e instituições preocupados com a mudança dos rumos da Educação Física foram capazes de reconfigurar toda a paisagem do debate acadêmico da área no Brasil. Falamos do debate acadêmico, ou do campo acadêmico, justamente devido às dificuldades de tradução das ideias do Movimento Renovador para o chão da escola. É possível dizer, e já de modo questionável, que a ideia de uma Educação Física crítica, reflexiva e até mesmo revolucionária, obteve bem mais adesão nas discussões acadêmicas e nas políticas educacionais (em menor grau), do que propriamente nas práticas pedagógicas desenvolvidas nas escolas.

Essa questão é interessante, visto que poderíamos refletir sobre se o conteúdo das mensagens do Movimento Renovador não seria arbitrário ou mesmo impositivo e legislador para professores que já atuavam com a Educação Física escolar há certo tempo e dentro de uma determinada tradição (MACHADO; BRACHT, 2016; FURTADO; BETTI, 2019). Do nosso ponto de vista, cabe observar a seguinte questão: na aproximação entre educação e Educação Física não construímos um discurso que de certo modo privilegiou uma forma de ensino-aprendizagem estranha ao universo das práticas corporais? Melhor dizendo, até que ponto a vinculação da Educação Física com o debate educacional crítico brasileiro não fez com que a linguagem da área passasse a ser colonizada pelas formas cognitivistas da Pedagogia?

\footnotetext{
${ }^{7}$ Sobre reduzir o trabalho exclusivamente à produção material, Duarte (2012, p. 98) escreveu: "isso seria identificar trabalho com trabalho manual e seria abdicar do horizonte de superação da divisão entre trabalho manual e trabalho intelectual. [...] Isso significa que o ser humano estaria reduzido às atividades de sobrevivência".
} 
Se no passado o seu status quo se deu pela tutela das ciências biológicas, atribuindo-lhe "cientificidade", parece que ao inserir-se no debate crítico educacional o seu objetivo maior era provar perante as outras ciências (Língua Portuguesa, História, Matemática, Geografia etc.) sua função educacional; que tinha muito a contribuir com a cognição dos alunos (consciência crítica); que não era apenas uma disciplina do fazer por fazer, mas que dava um salto qualitativo da aptidão física para a reflexão crítica sobre as formas de representação do homem no mundo - formas estas meramente exteriorizadas pelo corpo.

Para o exame dessa questão, optamos pela análise de expressões do Movimento Renovador da Educação Física brasileira ligadas ao marxismo. Essa opção se justifica devido ao marxismo se apresentar como uma destacada vertente dentre todos os projetos emancipatórios produzidos na modernidade ${ }^{8}$. Na Educação, encontramos a construção da pedagogia histórico-crítica como uma manifestação notável desse projeto. Na Educação Física, temos a presença de um conjunto de produções intelectuais críticas ao esporte, ao lazer, ao corpo, a saúde etc., que nos termos da década de 1980 podem ser identificadas como adeptas à Educação Física revolucionária, crítica ou progressista (BRACHT, 1997).

Para melhor exposição e compreensão do conjunto desta produção teórica e do lugar do corpo dentro do debate marxista da Educação Física brasileira, inicialmente, fazemos uso da proposição de Furtado e Borges (2018) a respeito da tipologia da produção de conhecimento progressista da Educação Física entre 1980 e 1995. De acordo com os autores, é possível identificar a presença de três grandes eixos e preocupações da produção teórica deste período, a dizer: Obras de denúncia (histórica, de conjuntura etc.), Denúncia e exposição de estudo ou experiência, Crítica e proposição metodológica de ensino.

No campo das obras de denúncia, temos as produções que, em um primeiro momento, se preocuparam em apresentar uma crítica aos fundamentos políticos, sociais e epistemológicos que ancoravam o projeto de dominação do corpo no campo das práticas corporais. Tais obras, seja por via da crítica radical a cisão entre corpo e mente na Educação Física, com destaque para Medina (1983; 1987) e Santin (1987), da análise histórica das funcionalidades da Educação Física em prol do desenvolvimento do projeto do capital, como é o caso de Castellani Filho (1988) e Soares (1994), ou da crítica aos usos do esporte e lazer como ideologia na sociedade brasileira, como propõe Cavalcanti (1984), contaram com influências do marxismo, da fenomenologia e de outras abordagens para a consolidação de uma crítica que pudesse perspectivar outros caminhos para a Educação Física brasileira.

\footnotetext{
${ }^{8}$ Cabe dizer que existem "marxismos e marxismos", bem como várias outras teorias e epistemologias preocupadas com a emancipação social.
} 
O que é interessante notar nestas obras, é que apesar da crítica marxista por vezes parecer pouco consistente no que diz respeito ao que fazer com manifestações da cultura corporal historicamente vinculadas ao mundo do capital, como o esporte, é possível perceber que o marxismo e as obras de Marx e Engels aparecem como uma via para o questionamento do uso instrumental do corpo na sociedade brasileira e na Educação Física escolar. Nesse sentido, Medina (1987) chega a discutir as relações entre política, educação e corpo na sociedade brasileira, afirmando a ideia de que toda a dominação e opressão encontram viabilidade na materialidade corpórea do brasileiro. Por isso, dá mais plena compreensão materialista do corpo, afirma o autor que:

É, portanto, no corpo - este sistema bioenergético-dialético - que está depositada toda a potencialidade revolucionária dos dominados e oprimidos. Sendo assim, todo o processo de libertação deve necessariamente passar pelo corpo-libidinal, fonte do desejo que pela solidariedade radical conquista as transformações sociais concretas (MEDINA, 1987, p. 71).

Na acepção de Medina (1987), que, aliás, apresenta o seu projeto de uma nova pedagogia do corpo em diálogo com o materialismo de Marx e Engels, com a fenomenologia de Merleau-Ponty e com as contribuições de Michael Foucault, para uma Educação Física que se alvora merecedora do adjetivo de revolucionária, não faz sentido a construção de discursos sobre e para a prática pedagógica que desprezem a condição humana de ser corpo. Na mesma perspectiva, Bracht (1999) propõe uma inflexão no debate sobre a ideia de consciência crítica na Educação Física, questionando se seria possível pensar em formação de consciência crítica desatrelada da experiência corporal.

Ainda de acordo com Bracht, a questão se coloca da seguinte forma: "a criticidade ou a educação crítica em EF somente pode acontecer através de um discurso crítico sobre o movimento? É preciso não incorrer no erro de entender criticidade, neste caso, apenas como um conceito da esfera da cognição.” (1999, p. 52). Em recente pesquisa, Bracht (2019) afirma que é fundamental para a construção de um universo simbólico de legitimação da Educação Física na contemporaneidade reconectar o corpo com a experiência formativa, porém, sem cair em uma falsa polarização com a consciência e os conceitos, mas sim, considerando a necessidade de a experiência incorporar o próprio pensamento.

Do ponto de vista das produções denominadas por Furtado e Borges (2018) como obras de denúncia, ou em certos casos também nas de denúncia e exposição de estudo ou experiências ${ }^{9}$, o

\footnotetext{
${ }^{9}$ No caso das obras de denúncia e exposição de estudo e experiências, Furtado e Borges (2018, p. 520) destacam as produções "[...] que fizeram a similar denúncia à educação física tradicional, todavia, com foco em estudos de caso, reflexões sobre temas emergentes na área, experimentação de vivências concretas e discussão de possíveis programas
} 
marxismo aparece como uma ferramenta preciosa para a crítica à opressão ao corpo na sociedade brasileira e na Educação Física escolar. Todavia, constatamos como problema maior as imprecisões de que a crítica necessita se transformar em proposição didático-pedagógica. Sendo assim, expomos novamente a nossa argumentação de que a proximidade do Movimento Renovador da Educação Física com os dizeres e as linguagens das teorias educacionais críticas, apesar de todos os avanços trazidos para a área, fez com que os objetivos e as contribuições para a emancipação humana fossem pensados em termos que oscilam entre o cognitivismo e a valorização da experiência corporal. Para melhor compreensão desta questão, retornamos a análise de Soares et al. (1992).

Em Soares et al. (1992), temos inegavelmente uma obra que apresenta fortes argumentos na direção da defesa da Educação Física como componente da educação escolar. Isto é, para a pretensão de explicação da realidade social complexa e contraditória, não basta que a escola socialize os conhecimentos oriundos das "disciplinas clássicas" como História, Geografia, Matemática, Português etc. Por isso, é preciso compreender que a expressão corporal como linguagem, expressa em atividades corporais na forma de jogos, esportes, lutas, danças e outras experiências corporais, deve também fazer parte do currículo escolar e, por consequência, de um projeto de escolarização crítico-superador.

Outro elemento importante de se considerar em Soares et al. (1992, p. 20) é o reconhecimento de que a especificidade do objeto de conhecimento da Educação Física refere-se "a expressão corporal como linguagem e como saber ou conhecimento". Todavia, é justamente nessa relação do reconhecimento do objeto da Educação Física como uma dimensão da cultura que se expressa pelo corpo, e os fins e meios da educação escolar, que a obra em questão tende a privilegiar, no processo escolar de compreensão da cultura corporal, os termos e a linguagem da Pedagogia - que tradicionalmente apontam para a primazia da consciência sob a experiência corporal.

No debate sobre a compreensão de currículo ampliado, Soares et al. (1992) em nenhum momento sinalizam para uma função protagonista do corpo e da experiência corporal no processo de compreensão dos conhecimentos escolares. Aliás, a própria definição apresentada pelos autores remete a um processo que se dá no pensamento, pois, "por essa razão se afirma o entendimento de que o conhecimento é uma representação do real no pensamento" (SOARES et al., 1992, p. 22). Dessa forma, se o conhecimento é uma representação do real no pensamento, poderíamos inferir que cabe então à Educação Física escolar fazer com que o conhecimento das práticas corporais seja assimilado pelos estudantes na forma de representação mental.

de ensino". Como exemplo principal dessa tipologia de produção do conhecimento progressista, os autores ressaltam o trabalho de Lovisolo (1995). 
Outro aspecto que sustenta a ideia de que na pedagogia marxista da Educação Física, elaborada por Soares et al. (1992), existe uma secundarização do corpo como meio de aprendizagem e produção de conhecimento pode ser constatado tanto nos chamados princípios curriculares no trato com o conhecimento, como na proposta dos ciclos de escolarização ${ }^{10}$. Em ambos os tópicos, novamente, o corpo e a experiência sensível são colocados em segundo plano. Por exemplo, nos princípios curriculares, dentre vários fundamentos apenas cognitivistas, defendese que os conhecimentos precisam ser adequados às possibilidades sociocognitivas dos alunos e a organização dos conteúdos deve obedecer à espiralidade da incorporação das referências do pensamento. Sem a pretensão de negar o mérito e nem a profundidade dos princípios apresentados, nossa indagação procura questionar por quais razões as estruturas cognitivas devem ser privilegiadas no processo de seleção de conhecimentos que se expressam eminentemente pelo corpo?

Na proposta dos ciclos de escolarização, fica evidente a ideia de que a escola precisa superar o estágio da experiência sensível em prol de capacidades como categorizar, classificar, estabelecer relações e generalizar os chamados conhecimentos científicos. Assim, a ideia defendida é que o processo de escolarização caminhe nesta direção, pois, no denominado ciclo de organização da identidade dos dados da realidade (pré-escola até a $3^{\mathrm{a}}$ série - nos termos da época), “[...] o aluno se encontra no momento da 'experiência sensível', onde prevalecem as referências sensoriais na sua relação com o conhecimento. O aluno dá um salto qualitativo nesse ciclo quando começa a categorizar os objetos, classificá-los e associá-los.” (SOARES et al., 1992, p. 23).

Nos termos de Soares et al. (1992), podemos constatar que as experiências sensíveis e corporais, na verdade, remetem a uma forma de conhecimento identificado com o senso comum e a vida cotidiana que, com efeito, a escola precisa superar no decorrer dos diferentes níveis de escolarização, por via da assimilação de representações mentais na forma de conceitos científicos. Esta ideia, de que pelo corpo e o movimento não seria possível alcançar a problematização teórica e a elaboração conceitual, pode apresentar desdobramentos metodológicos, na medida em que, de acordo com Soares et al. (1992, p. 29), existem lugares destinados para o fazer e outros para o pensar na escola, qual seja, “a quadra ou o campo para o jogo, a sala de aula para a reflexão pedagógica sobre ele, o recreio para uma 'pelada', um campeonato para constatar os dados, identificar as classificações, as generalizações etc.".

\footnotetext{
${ }^{10}$ Em Melo, Lavoura e Taffarel (2020) o leitor poderá encontrar uma atualização da proposta dos ciclos de escolarização de Soares et al. (1992). Apesar dos significativos avanços teóricos e das incorporações de referenciais do campo marxista, persiste na produção a ideia de que os conteúdos escolares podem ser definidos apenas considerando os processos e as estruturas mentais que constituem os indivíduos.
} 
Tendo em vista a superação prática da dicotomia entre pensamento e experiência corporal instaurada na Educação Física escolar desde sua gênese na escola moderna e reforçada por sua produção teórica concebida como crítica e revolucionária no Brasil, no tópico seguinte arriscamonos a discutir possibilidades e possíveis desdobramentos de uma nova compreensão da relação entre escola, corpo e Educação Física.

\section{NOTAS PARA REDIRECIONAR A DISCUSSÃO: por uma escola com corpo}

Como se pôde notar ao longo deste estudo, nossas reflexões gravitaram, de maneira geral, em torno da questão elementar que é a relação entre escolarização e Educação Física, ou, para sermos mais específicos, escolarização e corpo/práticas corporais. A rigor, podemos dizer que este é um trabalho que se debruça sobre a razão de ser da Educação Física no currículo escolar, uma vez que a sua própria legitimidade passa, invariavelmente, por uma reflexão rigorosa sobre objetos de conhecimentos específicos à sua área. Trata-se de um tema complexo que, obviamente, não se esgota nestas poucas páginas. Os seus desdobramentos atravessam a cultura, a política, a economia e a sociedade. Provoca tensões epistemológicas. Estamos, afinal, diante de uma "[...] tarefa que é acima de tudo uma demanda do tempo presente" (FURTADO, 2020, p. 159).

É importante também que este estudo não seja compreendido pela ótica da "negação", ou seja, onde aquilo que melhor o define "[...] é a sua negação das formas clássicas de educação escolar" (DUARTE, 2010, p. 33). Ao colocarmos o corpo no centro do debate epistemológico, estamos reivindicando por um espaço no currículo escolar que foi historicamente projetado contra as manifestações culturais que se expressam no corpo, com o corpo.

Logo, não se trata aqui, sob hipótese alguma, de militar pela exclusão das disciplinas escolares que trabalham mais ligadas à cognição dos alunos e alunas, mas de somar às suas aprendizagens e formação o corpo e as práticas corporais. Pensando com Furtado (2020), é no mínimo inaceitável que, ainda hoje, a Educação Física não constitua de forma consistente e logicamente organizada no currículo, o processo de escolarização de crianças, jovens e adultos. $\mathrm{O}$ que melhor define, portanto, este trabalho não é, como já dissemos, a negação, mas a afirmação: afirmar o lugar do corpo e das práticas corporais na cultura escolar.

A intenção de refletir sobre categorias específicas de intervenção - o corpo e, por extensão, as práticas corporais - deu-se no sentido de que, apesar de muito se falar no meio educacional em não dividir o humano em "corpo" e "mente", o que vemos muitas vezes é uma fragmentação velada. Fala-se, como um jargão, de se opor à cisão corpo-mente ao mesmo tempo que o corpo e as práticas corporais surgem nesses discursos instrumentalizados em prol da melhor assimilação do conteúdo 
ou da "consciência crítica". O corpo, serviçal da alma, do trabalho e da moralidade, ressurgi novamente, desta vez como serviçal do intelecto na forma de representação mental. Nesta perspectiva, não há espaço para pensar o corpo e as práticas corporais com valor em si. Brincar e jogar, por exemplo, não são concebidos como momentos privilegiados da cultura lúdica, onde a criança, o jovem ou o adulto experimentam novas formas de ser no mundo, produzem novos sentidos, ressignificam informações, criam valores e compõem relações com objetos, ou, em linguagem antropológica, artefatos.

Com efeito, o que estamos propondo neste texto, que se direciona aos atores da Educação Física brasileira, é que façamos uma reflexão radical sobre temas específicos do campo, na qual a discussão sobre corpo e práticas corporais seria apenas o primeiro movimento nesta direção, já que a própria estrutura (física e teórica) escolar foi historicamente projetada de modo a negar e imobilizar a corporalidade dos indivíduos. O que a história tem nos mostrado, especialmente da década de 1980 para cá, é que não se constrói uma hegemonia, no sentido de Gramsci, apenas com um discurso crítico. Por exemplo, os próprios defensores das pedagogias críticas, de natureza marxista, reconhecem que os professores da educação básica, por falta de referências concretas, estão tendo “[...] dificuldade de organizar/planejar/sistematizar o ensino da Educação Física com base na perspectiva da reflexão sobre a cultura corporal" (REIS et al., 2013, p. 16).

Assim, não cabe para este trabalho aquela velha e oportunista crítica que acusa os debates que giram em torno de temas específicos da Educação Física de incorrerem no crasso erro de tratar a educação, no geral, e a Educação Física, em particular, como autônomas e desconectadas da política e da sociedade. Talvez desvinculado mesmo da política e da sociedade estejam os discursos que se arrogam críticos, mas que não conseguem alcançar o chão da escola. Materialismo sem materialidades. Pedagogia sem práxis. Marxismo sem Marx. Como questiona Furtado (2020, p. 164), “[...] será se o professor poderá apenas ministrar aula com o seu discurso pedagógico de orientação crítica sem dominar os conhecimentos específicos que devem ser ensinados para a comunidade estudantil?" Nas palavras do próprio Marx, saber se cabe ao pensamento humano alguma verdade objetiva não é uma questão da teoria, mas uma questão prática.

\section{REFERÊNCIAS}


ALMEIDA, Felipe; BRACHT, Valter; VAZ, Alexandre. Educação Física, pedagogia crítica e ideologia: gênese e interpretações. Movimento, Porto Alegre, v. 21, n. 2., p. 317-331, abr.jun. de 2015.

ADORNO, Theodor. Educação e emancipação. 2. ed. São Paulo: Paz e Terra, 2020.

BRACHT, Valter. A educação física escolar no Brasil: o que ela vem sendo e o que ela pode ser (elementos de uma teoria pedagógica da educação física). Ijuí: Ed. Unijuí, 2019.

BRACHT, Valter. Educação física e Ciência: cenas de um casamento (in)feliz. Ijuí: Unijui, 1999.

BRACHT, Valter. Educação Física e aprendizagem social. 2. ed. Porto Alegre: Magister, 1997.

BRACHT, Valter. Coletivo de Autores: a cultura corporal em questão. IN: Soares et al.

Metodologia do ensino de educação física. São Paulo: Cortez, 2012.

BRACHT, Valter; ALMEIDA, Felipe. Pedagogias críticas da Educação Física: gênese e interpretações. Movimento, Porto Alegre, v. 25, e25001, 2019.

BRACHT, Valter; ALMEIDA, Ueberson; WENETZ, Ileana (orgs.). A educação física escolar na américa do sul: entre a inovação e o abandono/desinvestimento pedagógico. Curitiba: Editora CRV, 2018.

BRASIL. Base Nacional Comum Curricular: Educação é a base. Ministério da Educação, 2017.

BRASIL, PRESIDÊNCIA DA REPÚBLICA. Lei $\mathbf{N}^{\mathbf{0}}$ 13. 415, de 16 de fevereiro de 2017: institui a Política de Fomento à Implementação de Escolas de Ensino Médio em Tempo Integral.

CASTELLANI FILHO, Lino. Educação física no Brasil: a história que não se conta. Campinas, SP: Papirus, 1988.

CAVALCANTI, Kátia. Esporte para todos: um discurso ideológico: São Paulo: Ibrasa, 1984.

DEBORTOLI, José Alfredo Oliveira; SAUTCHUK, Carlos Emanuel. Técnica, corpo e arte: aproximações entre antropologia e motricidade. Licere, Belo Horizonte, v. 16, n. 2, jun/2013.

DELEUZE, Gilles. Conversações. 1 $^{\text {a }}$ ed. São Paulo: Editora 34, 1992.

DESCARTES, René. Discurso do método. 2. ed. São Paulo: Editora escala, 2009.

DUARTE, Newton. Luta de classes, educação e revolução. In: SAVIANI, D.; DUARTE, N (Orgs.). Pedagogia histórico-crítica e luta de classes na educação escolar. Campinas, SP: Autores Associados, 2012.

DUARTE, Newton. O debate contemporâneo das teorias pedagógicas. In: MARTINS, Lígia Márcia; DUARTE, Newton (orgs.). Formação de professores: limites contemporâneos e alternativas necessárias [online]. São Paulo: Editora UNESP; São Paulo: Cultura Acadêmica, 2010.

FOUCAULT, Michael. Microfísica do poder. Rio de Janeiro: Edição Geral, 1979.

FREIRE, João Batista. Educação de corpo inteiro: Teoria e prática da educação física. São Paulo: Editora Scipione, 1989. 
FREIRE, Paulo. Conscientização: teoria e prática da libertação: uma introdução ao pensamento de Paulo Freire. São Paulo: Cortez \& Moraes, 1979.

FREIRE, Paulo. Pedagogia do oprimido. 13 ed. São Paulo: Paz e Terra, 2010.

FURTADO, Renan Santos. Práticas corporais e Educação Física escolar: sentidos e finalidades. Corpoconsciência, Cuiabá-MT, vol. 24, n. 3, p. 156-167, set./ dez., 2020.

FURTADO, Renan; BETTI, Mauro. Summum jus, summa injuria: os acadêmicos como legisladores e a BNCC-Educação Física. Movimentalidade, Plataforma de criação de saberes diagonais, 2019.

FURTADO. Renan; BORGES, Nazareno. Educação Física Brasileira entre 1980 e 1995: novos olhares sobre a produção do conhecimento. Filos. e Educ., Campinas, SP, v.10, n.3, p. 506-535, set./dez. 2018.

GONÇALVES, Maria Augusta Salim. Sentir, Pensar, agir - Corporeidade e educação. Campinas, SP: Papirus, 1994.

INGOLD, Timothy. Da transmissão de representações à educação da atenção. Educação, Porto Alegre, v. 33, n. 1, p. 6-25, jan./abr. 2010.

KUNZ, Elenor. Transformações Didático-Pedagógicas do Esporte. Ijui: Unijuf, 1994.

KUNZ, Elenor. Práticas didáticas para um "Conhecimento de Si" de Crianças e Jovens na Educação Física. In: KUNZ, Elenor (Org.). Didática da Educação Física 2. 4ª ed. Ijuí: Ed. Unijuí, 2012.

LOVISOLO, Hugo. Educação física: arte da mediação. Rio de Janeiro: Sprint Editora, 1995.

MACHADO, Thiago; BRACHT, Valter. O impacto do movimento renovador da Educação Física nas identidades docentes: uma leitura a partir da "teoria do reconhecimento" de Axel Honneth. Movimento, Porto Alegre, v. 22, n. 3, 849-860, jul./set. de 2016.

MACHADO; Thiago da Silva et. al. As práticas de desinvestimento pedagógico na Educação Física escolar. Movimento, Porto Alegre, v. 16, n. 02, p. 129-147, abril/junho de 2010.

MALDONADO, Daniel. Inovação na Educação Física escolar: desafiando a previsível imutabilidade didático-pedagógica. Pensar a Prática, Goiânia, v. 21, n. 2, abr./jun. 2018.

MARX, Karl. A ideologia alemã: crítica da mais recente filosofia alemã em seus representantes Feuerbach, B. Bauer e Stirner, e do socialismo alemão. São Paulo: Boitempo: 2007.

MARX, Karl. Processo de trabalho e processo de valorização. In: MARX, Karl. O Capital: crítica da economia política. Vol. 1, Livro 1. Trad. Regis Barbosa e Flávio Kothe. São Paulo: Editora Nova Cultural, 1996.

MARX, Karl. O capital: crítica da economia política. Livro I. Trad. Rubens Enderle. São Paulo: Boitempo, 2013.

MEDINA, João Paulo. A educação Física cuida do corpo... e "mente": Bases para a renovação e transformação da educação Física. Campinas: Papirus, 1983. 
MEDINA, João Paulo. O brasileiro e seu corpo: educação e política do corpo. Campinas: Papirus, 1987.

MELO, Flávio; LAVOURA, Tiago; TAFFAREL, Celi. Ciclos de escolarização e sistematização lógica do conhecimento no ensino crítico-superador da educação física: contribuições da teoria da atividade. Revista Humanidades e Inovação v.7, n.10 - 2020.

REIS, Adriano de Paiva et al. Introdução. In: REIS, Adriano de Paiva; PEREIRA, Carla Cristina Carvalho; PINA, Leonardo Docena; LANDIM, Renata Aparecida Alves (Orgs.). Pedagogia

Histórico-Crítica e Educação Física. Juiz de Fora: Editora UFJF, 2013.

SANTIN, Silvino. Educação Física: uma abordagem filosófica da corporeidade. Porto alegre: UNIJUÍ, 1987.

SAVIANI, Demerval. Escola e democracia. 42a ed. Campinas, SP: Autores Associados, 2012.

SILVA, Ana Márcia. Entre o corpo e as práticas corporais. Rev. Arquivos em Movimento, Rio de Janeiro, Edição Especial, v.10, n.1, p.5-20, jan/jun 2014.

SOARES, Carmen Lúcia; TAFFAREL, Celli Nelza Zulke; VARJAL, Elizabeth; CASTELLANI FILHO, Lino; ESCOBAR, Micheli Ortega; BRACHT, Valter. Metodologia do ensino da Educação Física. São Paulo: Cortez, 1992.

SOARES, Carmen. Educação física: raízes europeias. 4. ed. Campinas, SP: Autores Associados, 2007.

VAZ, Alexandre. Certa herança marxista no recente debate da educação física no Brasil.

Movimento, Porto Alegre, v. 25, e25069, 2019.

\section{NOTAS DE AUTOR}

AGRADECIMENTOS - Não se aplica.

CONTRIBUIÇÃO DE AUTORIA - Não se aplica.

FINANCIAMENTO - Não se aplica.

CONSENTIMENTO DE USO DE IMAGEM - Não se aplica

APROVAÇÃO DE COMITÊ DE ÉTICA EM PESQUISA - Não se aplica.

CONFLITO DE INTERESSES - Não se aplica.

\section{LICENÇA DE USO}

Os autores cedem à Motrivivência - ISSN 2175-8042 os direitos exclusivos de primeira publicação, com o trabalho simultaneamente licenciado sob a Licença Creative Commons Attribution Non-Comercial ShareAlike (CC BY-NC SA) 4.0 International. Esta licença permite que 
terceiros remixem, adaptem e criem a partir do trabalho publicado, desde que para fins não comerciais, atribuindo o devido crédito de autoria e publicação inicial neste periódico desde que adotem a mesma licença, compartilhar igual. Os autores têm autorização para assumir contratos adicionais separadamente, para distribuição não exclusiva da versão do trabalho publicada neste periódico (ex.: publicar em repositório institucional, em site pessoal, publicar uma tradução, ou como capítulo de livro), com reconhecimento de autoria e publicação inicial neste periódico, desde que para fins não comerciais e compartilhar com a mesma licença.

\section{PUBLISHER}

Universidade Federal de Santa Catarina. Programa de Pós-Graduação em Educação Física. LaboMídia - Laboratório e Observatório da Mídia Esportiva. Publicado no Portal de Periódicos UFSC. As ideias expressadas neste artigo são de responsabilidade de seus autores, não representando, necessariamente, a opinião dos editores ou da universidade.

\section{EDITORES}

Mauricio Roberto da Silva, Giovani De Lorenzi Pires, Rogério Santos Pereira.

\section{EDITOR DE SEÇÃO}

Silvan Menezes dos Santos

REVISÃO DO MANUSCRITO E METADADOS

João Caetano Prates Rocha; Keli Barreto

\section{HISTÓRICO}

Recebido em: 06 de abril de 2021.

Aprovado em: 24 de junho de 2021. 